\title{
Broadening Discourse on Responsible Research and Innovation (RRI)
}

\author{
Christopher Coenen
}

Published online: 9 March 2016

C) Springer Science+Business Media Dordrecht 2016

In recent years, notions of "responsible innovation" and, particularly in Europe, "responsible research and innovation" (RRI) - have become very widespread in academic and political discourse on science and technology. Overarching goals have been defined for RRI at the level of the European Union (EU), including a better alignment of science (policies) with societal needs and the consideration of ethical aspects, the stimulation or implementation of inclusive and deliberative processes (stakeholder involvement and public engagement), and the sharing of responsibility for innovation processes among a wide range of stakeholders by means of early engagement and mutual learning (for example, by means of what are known as "mobilisation and mutual learning action plans", MMLAPs). The conceptual work on RRI is still ongoing and may be deemed a process innovation, for example as far as the following five aspects are concerned: societal engagement, gender equality and gender in research and innovation content, open access, science education and ethics.

Using tools such as MMLAPs, research policy aims to stimulate discourse on science and technology issues in a highly inclusive fashion in terms of both the target groups it addresses (the general public and the great diversity of actual and potential stakeholders in science and technology issues) and the thematic scope of the discussions and

\section{Coenen $(\bowtie)$}

Institute of Technology Assessment and Systems Analysis (ITAS), Karlsruhe Institute of Technology (KIT), POB 3640,

76021 Karlsruhe, Germany

e-mail: christopher.coenen@kit.edu other activities. One example is the MMLAP NeuroEnhancement: Responsible Research and Innovation (NERRI) [http://www.nerri.eu], which sought to foster productive dialogue between potential users, potential "designers" (researchers, engineers and developers) and legislators who will potentially play a part in setting the legal framework for neuro-enhancement technologies before products start to hit the marketplace. Under the MMLAP Synthetic Biology - Engaging with New and Emerging Science and Technology in Responsible Governance of the Science and Society Relationship (SYNENERGENE) [http://www.synenergene.eu], we have not only involved stakeholders from science, industry and policymaking, but also from a wide variety of civil society organisations with very different political agendas, as well as educators and, to an unusually large extent, artists and art institutions. The project has incorporated artistic activities on the basis of an understanding of art as a cultural domain with its "own logic" different from, for example, instrumentalist logic.

From this perspective, art is not a means to an end in the context of RRI (deployed, for example, to generate public attention or involve citizens, although "formats" from art, such as drama, can be exploited for these purposes), but contributes, in a Habermasian sense, to normative communicative action. Much in line with Habermasian thinking, RRI activities and discussions about them at EU level often focus on the rational evaluation of, and public accountability in, science and technology matters [1]. Jürgen Habermas distinguishes between the domains of the instrumental, the moralpractical and the aesthetic, which correspond to three 
validity claims: cognitive truth, normative rightness and subjective expressiveness. In his view, communicative action based on normative reason is crucial for democratic social interaction, and aesthetic works cannot coordinate action in this way [2]. Aesthetic experience, however, can, as he argued, permeate our cognitive significations and normative expectations, change the manner in which they refer to one another, and renew the interpretation of our needs that informs how we perceive the world. Accordingly, art is a domain for itself but, through its public reception, can significantly contribute to normative communicative action on science and technology - and thus to the social shaping of such fields.

In her article in the present issue of NanoEthics: Studies of New and Emerging Technologies, Nora Vaage discusses the ethics of bioart and how the latter can impact on ethical discourse. She argues that living artworks created with biotechnology raise a range of ethical questions, some of which are unprecedented, others well known from other contexts. Vaage points out that discussions of ethical issues in bioart do not refer to existing discourses on art and morality familiar from the field of aesthetics. She also proposes an integrated approach which may permit a more profound understanding of ethical issues in bioart, inspire new ways of thinking about ethics in relation to art in general, and impart novel stimuli to bioethics and technology assessment. While this journal welcomes submissions on all kinds of studies dealing with art and technology, and takes it for granted that the analysis of cultural discourse is crucial for understanding and shaping research and innovation (see, for example, [3]), approaches such as the one taken by Vaage, which focus on the reciprocal influencing of artistic practices and the ethics of technology, are of particular interest with a view to RRI and thus for this journal.

The current further broadening of RRI discourse is also reflected by other contributions to the present issue of NanoEthics. Jeong Joo Ahn, Youngjae Kim, Elizabeth Corley and Dietram Scheufele, for example, point out in their article that, although some regulatory frameworks for the occupational health and safety of nanotechnology workers have been developed, worker safety and health issues in these laboratory environments have received less attention than many other areas of nanotechnology regulation. They provide a US-centred analysis of current guidelines and identify needs for policy action, specifically with regard to the issue of workers' participation in the process of establishing safety measures, and the development and enforcement of more unified (and mandatory) guidelines. With more such studies to be conducted, we may hope that certain socio-economic and political blind spots in RRI discourse will be eliminated.

In another article on nanotechnology in the present issue, Xi Wang revisits "upstream" public engagement from a Habermasian perspective. After pointing out that the idea of conducting upstream public engagement with nanotechnology has been subjected to criticism for its isolation from processes within the political system, the author explores the capacity of civil society organisations (CSOs) to distil, raise and transmit societal concerns in an amplified form to public spheres at the EU level. Based on content analysis and semi-structured interviews with relevant actors, Wang examines the evolution of CSO approaches to nanotechnology over the past decade and investigates whether, and how, upstream public engagement could contribute to more vibrant public spheres and facilitate the formation of communicative power. The author argues that moving public engagement "upstream" enables CSOs to be better informed and enter debates at an earlier stage, and highlights the fact that a "green alliance", comprised of different stakeholder groups, is taking shape and calling for more stringent regulation of nanomaterials. At the same time, upstream public engagement has proved to be unsuccessful in generating substantial and sustained interest among a large number of CSOs.

In their article, Max Boholm and Rickard Arvidsson deal with definitional issues that relate to nanomaterials and nanoparticles, in particular. They point out that scientific writings and policy documents define the terms "nanomaterial" and "nanoparticle" in various ways, and that this variation is considered problematic by some commentators because the absence of a shared definition is understood to be potentially hindering nanomaterial knowledge production and regulation. Others, however, would argue that the existence of a shared definition may itself cause problems, as rigid definitions arguably exclude important aspects of the phenomena that are studied. The authors provide an analytical framework for a systematic understanding of how, and even whether, nanomaterial and nanoparticles could and should be defined. Based on an extensive review of the definitions of 'nanomaterial' and 'nanoparticle', Boholm and Arvidsson apply theories from philosophy and linguistics in order to structure and categorise these definitions. They propose a 
framework intended to foster understanding for the process of defining "nanomaterial" and "nanoparticle". Both the generality needed for a shared understanding and the level of precision required for different purposes are taken into consideration in this framework.

François Roubert, Marie-Gabrielle Beuzelin-Ollivier, Margarethe Hofmann-Amtenbrink, Heinrich Hofmann and Alessandra Hool have contributed an article on nanostandardisation to the present issue. The authors argue that the lack of standardisation in the field of nanoscience and nanotechnology is a serious shortcoming as it has led to the acceptance of methods and results that do not ensure sufficient consistency and therefore, in their view, may possibly result in research outputs that are not as robust as they should be. By means of a detailed, contextualised analysis of a large, multidisciplinary European research and technology development project on nanotechnologybased diagnostic systems, the authors develop recommendations concerning the establishment of well defined methods to support the work of collaborative nanoparticle-based research and development projects, and enhance standardisation processes.

Since the 2000s, a growing body of philosophical and other analyses have discussed futuristic visions and the role played by such visions of the future in discourse on new and emerging science and technology, and this journal has been an important forum for these discussions since its very first issue. In the context of RRI discourse, it may be argued that the creation, popularisation and political uses of visions of the future should be analysed in terms of responsible action by players in science and innovation systems. In the present issue, Martin Sand provides a philosophical analysis of the role played by futuristic "visioneers" in discourse on new and emerging science and technology, dealing with such questions as autonomy and causation in relation to responsibility, and the problem of accountability in highly complex socio-technical systems. Based on his analysis, Sand warns against exaggerating the role of visioneers in discourse on new and emerging technoscience. Visioneers also play a key role in a fine book by my NanoEthics co-editor Colin Milburn, entitled Mondo Nano: Fun and Games in the World of Digital Matter. For the present issue, Stephanie Vasko has reviewed this book, which provides its readers with much food for thought and fascinating material on the representation of nanotechnologies in popular culture.

Always aiming to be a forum for lively debate, our journal is delighted when authors submit discussion notes. In the present issue, we have again published two such notes, one by Daniele Ruggiu and one by the biologist Manuel Porcar.

The discussion note by Porcar deals with synthetic biology, a field of new and emerging science and technology which has been analysed and discussed for quite some time in this journal and will continue to be covered by it. Dealing with key issues in current philosophical and scientific discussions about synthetic biology, above all the field's engineering paradigm, the author argues that living organisms are inherently non-machine, non-standardised entities and that the current state-of-the-art in synthetic biology combines pre- and post-standardisation efforts. Noting that there is no evidence full standardisation in biology is even possible, Porcar proposes a view of synthetic biology based on purpose rather than technicalities.

In his discussion note, Ruggiu responds to a critique of his ideas concerning the role of rights in an RRI context which was set out - in the course of a plea for a logic of care - by Christopher Groves in the last December issue of NanoEthics [4]. Ruggiu now argues that, thanks to the work of the European Court of Human Rights, human rights are continuously evolving in Europe and therefore constitute a framework that is open to the future. Through codes of conduct and similar instruments, human rights can give rise to moral practices at the world-regional and other levels. In Ruggiu's view, a rights-based framework is also more effective than an ethics of care when it comes to dealing with certain aspects of intergenerational relationships, such as genetic enhancement in humans. As already pointed out in my last editorial, I would very much like to see the discussion about the role of rights in RRI continued in this journal since it appears to be crucial for the study and governance of new and emerging technologies, and the further development of RRI discourse.

Besides deeper analyses of the political relevance and current designs of RRI activities - for example with a view to "upstream", public and stakeholder engagement exercises or the role of such institutions as the European Court of Human Rights, as well as the efforts to broaden and contextualise RRI discourse - for example by including artists in activities or by analysing a wide variety of cultural aspects of new and emerging technoscience -, more research and RRI activities on other political and socioeconomic aspects of research and innovation would be worthwhile. While studies like the one by Jeong Joo Ahn and his colleagues published in the present issue are important contributions to making RRI discourse more 
"socially specific", more work of this kind will be needed if we are to better understand the challenges and chances of RRI at a time of widespread social crisis.

\section{References}

1. Von Schomberg R (2013) A vision of responsible innovation. In: Owen R, Bessant JR, Heintz M (eds)
Responsible innovation: managing the responsible emergence of science and innovation in society. Wiley, Chichester, pp 51-74

2. Habermas J (1981) Modernity versus postmodernity. New Ger Crit 22:3-14

3. Kaiser M (2015) Reactions to the future: the chronopolitics of prevention and preemption. NanoEthics 9(2):165-177

4. Groves C (2015) Logic of choice or logic of care? Uncertainty, technological mediation and responsible innovation. NanoEthics 9(3):321-333 